JPPIPA, Vol.3 No.2 2018
Jttp://journal.unesa.ac.id/index.php/jppipa

\title{
PENERAPAN SISTEM POIN KEHADIRAN UNTUK MENANAMKAN KARAKTER DISIPLIN PADA MATA KULIAH MANAJEMEN SAINS
}

Oleh:

Masruroh

Universitas Islam Lamongan, Lamongan.

\begin{abstract}
Abstrak
Penelitian ini bertujuan untuk mendeskripsikan efektivitas penerapan sistem poin kehadiran untuk menanamkan karakter disiplin mahasiswa pada mata kuliah Manajemen Sains. Penelitian ini merupakan penelitian pre experimental dengan desain one group pre test post test. Data diambil dari 106 mahasiswa Teknik Informatika yang mengambil mata kuliah Manajemen Sains yang terbagi dalam 4 kelas. Data didapatkan melalui observasi dengan instrumen lembar pengamatan kehadiran mahasiswa. Karakter disiplin mahasiswa dinilai berdasarkan persentase mahasiswa yang datang terlambat lebih dari 30 menit selama perkuliahan. Pengamatan dilakukan selama satu semester. Semakin kecil persentase mahasiswa yang datang terlambat, semakin baik karakter disiplin tertanam. Data dianalisis menggunakan uji t untuk mengetahui efektivitas penerapan sistem poin kehadiran untuk menanamkan karakter disiplin mahasiswa pada mata kuliah Manajemen Sains. Hasil analisis data menggunakan uji t menunjukkan thitung sebesar 3,89 dan ttabel untuk $n=4$ dan $\alpha=0,05$ sebesar 2,35. Dari hasil penelitian ini dapat disimpulkan bahwa penerapan sistem poin kehadiran efektif untuk menanamkan karakter disiplin mahasiswa pada mata kuliah Manajemen Sains.
\end{abstract}

Kata Kunci : poin kehadiran,karakter, disiplin.

\begin{abstract}
This research is aimed to describe the effectiveness of attendance point system implementation to develop student's character of discipline in Management Science subject. This research is pre experimental research with one group pre test post test design. Data retrieved from 106 Informatics Engineering students who take Management Science subject which is divided into 4 classes. Data retrieved from observation method using attendance observation sheet. Student's character of discipline was assessed based on the percentage of student who come late more than 30 minutes during learning activity. The observation was done during one semester. The lower the percentage of student who come late, the better the character of discipline is developed. Data was analyzed using $t$ test to determine the effectiveness of attendance point system implementation to develop student's character of discipline in Management Science subject. The result shows that $t$ calculation is 3.89 and t tabel for $n=4$ and $\alpha=0,05$ is 2.35. Thus, it can be concluded that the attendance point system implementation is effective to develop student's character of discipline in Management Science subject.
\end{abstract}

Keywords: attendance point, character, discipline.

C 2018 Universitas Negeri Surabaya

Alamat Korespondensi:

Universitas Islam Lamongan, Lamongan

p-ISSN: 2527-7537

Email: masruroh@unisla.ac.id

e-ISSN: 2549-2209 


\section{PENDAHULUAN}

Menurut Kamus Besar Bahasa Indonesia (KBBI), kata disiplin memiliki arti ketaatan (kepatuhan) kepada peraturan (tata tertib dan sebagainya). Julaikhah dan Ismawati (2018) mendefinisikan disiplin sebagai rasa taat dan patuh terhadap nilai yang dipercaya sebagai tanggung jawabnya. Yusriani (dalam Chrismayanti, Tegeh, dan Tirtayani, 2016) menambahkan bahwa kedisiplinan mensyaratkan adanya pengendalian terhadap tingkah laku dan penguasaan diri. Dengan demikian, disiplin dapat didefinisikan sebagai sikap taat aturan yang didasari adanya pengendalian diri terhadap tingkah laku.

Disiplin merupakan salah satu karakter yang harus dimiliki oleh seseorang sebagai bekal untuk dapat menjadi masyarakat dan pribadi yang berkarakter positif. Bisa dibayangkan, tanpa adanya kedisiplinan kehidupan bermasyarakat akan menjadi tidak tertib. Pelanggaran tata tertib di lingkungan masyarakat menjadi hal yang biasa terjadi sebagai akibat kurangnya kedisiplinan masyarakat. Dari sudut pandang manusia sebagai pribadi pun juga demikian, karakter disiplin juga diperlukan seseorang untuk berhasil dalam kehidupannya. Wahyu, Akhyar, dan Maryana (2015) menyatakan bahwa disiplin merupakan modal utama atau kunci sukses seseorang. Sebagai contoh, seorang pekerja kantoran, misalnya, dituntut untuk disiplin masuk jam kerja, mengikuti peraturan tempat di mana dia bekerja, dan peraturan-peraturan lainnya. Dalam hal ibadah juga demikian, kita dituntut untuk disiplin waktu dalam mengerjakannya.

Salah satu tugas institusi pendidikan dari pendidikan dini sampai pendidikan tinggi adalah menanamkan karakter pada peserta didiknya. Hal ini sesuai dengan Undang-undang No 20 tahun 2003 tentang Sistem Pendidikan Nasional dimana disebutkan bahwa pendidikan nasional berfungsi mengembangkan kemampuan dan membentuk karakter serta peradaban bangsa yang bermartabat dalam rangka mencerdaskan kehidupan bangsa. Salah satu karakter tersebut adalah karakter disiplin yang merupakan satu dari delapan belas nilai karakter yang harus ditanamkan pada peserta didik menurut Departemen Pendidikan Nasional (2010).

Pada kenyataannya, karakter disiplin masih kurang tertanam dengan baik pada peserta didik, bahkan pada level mahasiswa sekalipun. Tindakan kurang disiplin seperti sering tidak mengikuti perkuliahan, terlambat masuk kelas saat perkuliahan, atau mengumpulkan tugas tidak tepat waktu masih sering dijumpai. Tindakan kurang disiplin seperti tersebut di atas, memang terlihat sepele. Meskipun demikian, hal tersebut apabila tidak segera dibenahi dikhawatirkan akan menjadi kebiasaan dan menjadi pemicu terjadinya tindakan kurang disiplin lainnya yang lebih besar. Hal ini seperti yang diungkapkan oleh Wuryandani, dkk. (2014) bahwa perilaku tidak disiplin yang dilakukan oleh peserta didik akan mempengaruhi perilaku menyimpang lainnya baik di lingkungan institusi pendidikan maupun meluas ke lingkungan masyarakat.

Berdasarkan hal tersebut di atas, maka diperlukan strategi untuk menanamkan kedisipilinan dalam kegiatan pembelajaran. Salah satu strategi yang dapat diterapkan adalah penerapan sistem poin kehadiran untuk meminimalkan kejadian keterlambatan mahasiswa dalam mengikuti kegiatan perkuliahan. Strategi poin kehadiran ini memanfaatkan penilaian sebagai sarana pembelajaran dalam hal ini untuk menanamkan karakter disiplin.

Sistem poin kehadiran ini memanfaatkan adanya penguatan berupa reward dan punishment. Penguatan yang dimaksud adalah pemberian reward kepada mahasiswa yang datang tepat waktu berupa poin kehadiran penuh atau poin bernilai 1 . Sedangkan punishment bagi mahasiswa yang datang terlambat lebih dari 30 menit berupa pemberian poin kehadiran separuh atau poin bernilai 0,5. Poin kehadiran ini selanjutnya digunakan sebagai dasar penilaian kehadiran mahasiswa. Penilaian kehadiran mahasiswa ini menjadi salah satu bagian penilaian untuk nilai akhir mahasiswa. Sehingga poin kehadiran ini akan mempengaruhi nilai akhir.

Penggunaan reward dan punishment dalam sistem poin kehadiran ini diharapkan dapat membuat mahasiswa lebih disiplin dalam mengikuti perkuliahan dengan hadir tepat waktu. Penggunaan reward dan punishment sebelumnya telah digunakan oleh Purnama (2017) dengan hasil setelah diterapkannya terapi behaviour dengan teknik reward dan punishment, para peserta didik yang meimiliki disiplin yang rendah mulai berubah sedikit demi sedikit.

Sistem poin kehadiran ini selain memanfaatkan adanya penguatan berupa reward dan punishment, juga memanfaatkan adanya motivasi ekstrinsik dari mahasiswa. Motivasi ekstrinsik yang dimaksud adalah motivasi untuk mendapatkan nilai yang bagus, baik nilai kehadiran maupun nilai akhir. Motivasi inilah yang mempengaruhi tingkah laku seseorang untuk mencapai tujuannya. Hal ini sesuai dengan definisi motivasi yang dikemukakann oleh Cleopatra (2015) di mana motivasi didefinisikan sebagai bagian dalam dari suatu keadaan yang menyebabkan seseorang bertindak dengan cara yang jelas untuk memenuhi tujuan tertentu. Dengan adanya sistem poin kehadiran, mahasiswa yang memiliki motivasi untuk mendapatkan nilai yang baik diharapkan akan terdorong untuk mengumpulkan poin kehadiran dengan maksimal dengan cara datang tepat waktu selama mengikuti perkuliahan. Dengan demikian, karakter disiplin diharapkan dapat tertanam dalam diri mahasiswa.

Dalam penelitian ini akan dideskripsikan bagaimana efektivitas penerapan sistem poin kehadiran untuk menanamkan karakter disiplin mahasiswa pada mata kuliah Manajemen Sains. 


\section{METODE}

Penelitian ini merupakan penelitian pre experimental dengan desain one group pre-test post-test. Data diambil dari 106 mahasiswa Teknik Informatika yang mengambil mata kuliah Manajemen Sains yang terbagi dalam 4 kelas sebagai sampel. Instrumen yang digunakan dalam penelitian ini adalah lembar pengamatan kehadiran mahasiswa. Pengamatan dilakukan selama satu semester.

Perlakuan yang diberikan dalam penelitian ini adalah pemberian poin untuk tiap kehadiran mahasiswa. Siswa yang datang tepat waktu akan diberikan poin 1 sedangkan mahasiswa yang datang terlambat lebih dari 30 menit akan diberikan poin 0.5. Poin tersebut dikumpulkan selama kegiatan perkuliahan dalam satu semester dan digunakan untuk menentukan nilai kehadiran mahasiswa yang berpengaruh pada nilai akhir mahasiswa pada mata kuliah Manajemen Sains.

Karakter disiplin mahasiswa dilihat dari persentase mahasiswa yang datang terlambat lebih dari 30 menit selama perkuliahan. Semakin kecil persentase mahasiswa yang datang terlambat, semakin baik karakter disiplin tertanam. Data kemudian dianalisis menggunakan uji $\mathrm{t}$ untuk mengetahui efektivitas perlakuan dengan rumus:

$$
t=\frac{M d}{\sqrt{\frac{\sum x^{2} d}{N(N-1)}}}
$$

(Arikunto, 2010)

Dengan:

Md : mean deviasi (d) antara post-test dan pretest

$\mathrm{Xd}$ : perbedaan deviasi dengan mean deviasi

$\mathrm{N}$ : banyaknya subjek

Perbedaan antara hasil pre-test dan post-test dinyatakan signifikan apabila thitung $\geqslant$ ttabel atau dapat dikatakan sistem poin kehadiran efektif untuk menumbuhkan karakter disiplin mahasiswa dalam mata kuliah Manajemn Sains, demikian sebaliknya.

Sebagai prasyarat uji t, sebelumnya dilakukan uji kenormalan menggunakan uji KolmogorovSmirnov untuk menentukan kenormalan data sampel. Data yang didapatkan kemudian terlebih dahulu bilangan bakunya menggunakan rumus:

$$
z_{i}=\frac{x_{i}-x}{s}
$$

(Sudjana, 2005)

Dengan:

$\mathrm{Zi}$ : bilangan baku data ke-i

xi : data ke-i $\mathrm{x}$ : rata-rata

$\mathrm{s} \quad$ : simpangan baku

Setelah didapatkan bilangan baku untuk tiap data, kemudian dihitung peluang $F(z i)$ menggunakan daftar distribusi normal baku dan dicari proporsinya $\mathrm{S}(z i)$. Selanjutnya di hitung selisish $\mathrm{F}(\mathrm{zi})$ dan $\mathrm{S}(\mathrm{zi})$ dengan harga mutlak. Dhitung adalah harga terbesar dari harga mutlak selisih F(zi) dan S(zi) tersebut. Data dinyatakan berasal dari populasi berdistribusi normal apabila Dhitung < Dtabel, demikian sebaliknya.

\section{HASIL DAN PEMBAHASAN}

Data persentase keterlambatan mahasiswa tiap kelas ditunjukkan dalam Gambar 1 berikut.

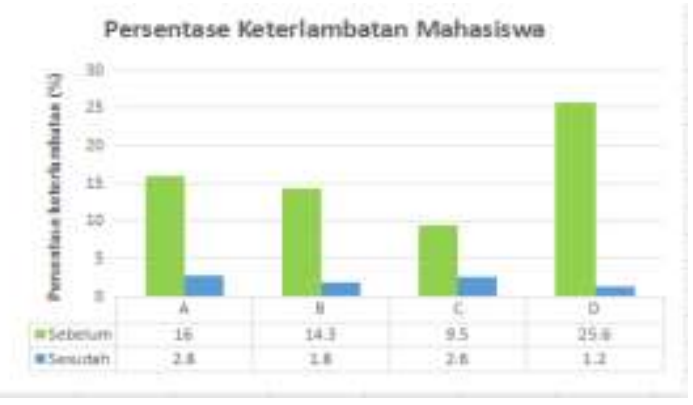

Gambar 1. Persentase Keterlambatan Mahasiswa

Dari gambar 1. dapat diketahui bahwa telah terjadi penurunan persentase keterlambatan mahasiswa sebelum dan sesudah diterapkannya sistem poin kehadiran. Pada kelas A, B, C dan D secara berturut-turut terjadi penurunan persentase keterlambatan mahasiswa sebesar 13,2\%, 12,5\%, $6,9 \%$, dan $24,4 \%$ dengan rata-rata persentase penurunan keterlambatan mahasiswa sebesar $14,25 \%$.

Hasil analisis kenormalan data menggunakan uji Kolmogorov-Smirnov menunjukkan $D_{\text {hitung }}$ sebesar 0,516 dan $\mathrm{D}_{\text {tabel }}$ sebesar 0,624, sehingga data yang didapatkan berasal dari distribusi normal. Berdasarkan hasil analisis tersebut maka dapat dilakukan uji $\mathrm{t}$ untuk menentukan efektivitas penerapan sistem poin kehadiran untuk menumbuhkan karakter disiplin mahasiswa.

Hasil analisis data menggunakan uji $\mathrm{t}$ menunjukkan $\mathrm{t}_{\text {hitung }}$ sebesar 3,89 dan $\mathrm{t}_{\text {tabel }}$ untuk $\mathrm{n}=$ 4 dan $\alpha=0,05$ sebesar 2,35, sehingga $t_{\text {hitung }} \geq t_{\text {tabel. }}$. Dengan demikian dapat dikatakan ada perbedaan yang signifikan antara hasil pre-test dan post-test atau sistem poin kehadiran efektif untuk menumbuhkan karakter disiplin mahasiswa dalam mata kuliah Manajemn Sains.

Adanya perbedaan yang signifikan antara persentase keterlambatan mahasiswa sebelum dan 
sesudah diterapkannya sistem poin kehadiran dimungkinkan karena adanya penguatan perilaku mahasiswa melalui pemberian reward dan punishment. Mahasiswa yang datang tepat waktu merasa diapresiasi dengan adanya pemberian poin kehadiran penuh. Sedangkan mahasiswa yang datang terlambat lebih dari 30 menit hanya akan diberikan poin kehadiran sebanyak 0,5 sebagai punishment. Mahasiswa yang datang terlambat juga diminta untuk menuliskan namanya di lembar absensi yang berlainan dengan daftar absensi reguler. Hal ini dimaksudkan agar mahasiswa yang bersangkutan merasa bahwa pemberian poin ini benar-benar diterapkan secara konsisten. Hal ini sejalan dengan hasil penelitian yang dilakukan oleh Purnama (2017) di mana setelah diterapkannya terapi behaviour dengan teknik reward dan punishment, para siswa yang meimiliki disiplin yang rendah mulai berubah sedikit demi sedikit.

Perbedaan yang signifikan antara persentase keterlambatan mahasiswa sebelum dan sesudah diterapkannya sistem poin kehadiran juga dimungkinkan karena adanya motivasi mahasiswa untuk mendapatkan nilai yang baik. Hal ini karena poin kehadiran ini menjadi dasar penilaian kehadiran mahasiswa. Penilaian kehadiran mahasiswa ini menjadi salah satu bagian penilaian untuk nilai akhir mahasiswa. Dengan demikian, mahasiswa yang ingin mendapatkan nilai akhir yang baik untuk mata kuliah ini terdorong untuk mengumpulkan poin kehadiran secara maksimal dengan cara datang tepat waktu selama kegiatan perkuliahan.

Sebagai tambahan, perbedaan yang signifikan antara persentase keterlambatan mahasiswa sebelum dan sesudah diterapkannya sistem poin kehadiran juga dimungkinkan karena adanya iklim kelas yang kondusif di mana pendidik juga mencontohkan karakter disiplin dengan hadir tepat waktu selama kegiatan perkuliahan. Hal ini dilakukan untuk menjaga agar iklim kelas kondusif untuk penerapan poin kehadiran sebagai sarana untuk menanamkan karakter disiplin di mana dosen sebagai role model juga mencontohkan karakter disiplin secara konsisten. Selain itu,, dengan dosen datang tepat waktu selama kegiatan perkuliahan akan memotivasi mahasiswa untuk datang tepat waktu. Hal ini sesuai dengan hasil penelitian yang dilakukan oleh Wulyandari, dkk (2014) yang menunjukkan bahwa iklim kelas yang kondusif merupakan hal penting yang harus diperhatikan dalam proses internalisasi karakter disiplin di institusi pendidikan.

\section{PENUTUP}

Dari hasil analisis data dan pembahasan dapat disimpulkan bahwa sistem poin kehadiran efektif untuk menumbuhkan karakter disiplin mahasiswa pada mata kuliah Manajemen Sains. Mengacu pada hasil penelitian, maka diharapkan penelitian selanjutnya menggunakan desain penelitian dengan menggunakan kelas kontrol, sehingga hasil yang didapatkan lebih akurat.

\section{DAFTAR PUSTAKA}

Arikunto, Suharsimi, 2010, Prosedur penelitian: Suatu Pendekatan Praktik. Jakarta, Rineka Cipta.

Chrismayanti, P. A., I Made Tegeh, dan Luh Ayu Tirtayani, 2016, Penerapan Metode Bermain Peran untuk Meningkatkan Perlaku Kedisiplinan pada Anak Usia 5-6 Tahun di PAUD Pradnya Paramita, eJournal Pendidikan Anak Usia Dini Universitas Ganesha, vol. 4 no. 3, diakses 29 Juli 2018, (https://ejournal.undiksha.ac.id/index.php/J JPAUD/article/download/8770/5691)

Cleopatra, Maria, 2015, Pengaruh Gaya Hidup dan Motivasi Belajar Terhadap Prestasi Belajar Matematika, Jurnal Formatif, vol. 5 no. 2 hh. 168-181.

Departemen Pendidikan Nasional, 2010, Bahan Pelatihan Penguatan Metodologi Pembelajaran Berdasarkan Nilai-nilai Budaya untuk Membentuk Daya Saing dan Karakter Bangsa, Jakarta, Pusat Kurikulum Departemen Pendidikan Nasional.

Kamus Besar Bahasa Indonesia (KBBI), 2018, disiplin, diakses 6 Agustus 2018, (https://kbbi.web.id/disiplin)

Purnama, Rizki, 2017, Terapi Behavior dengan Teknik reward dan Punishment dalam Meningkatkan Disiplin Diri Anak Usia Pra Sekolah Kelas TK A RA Darul Hafidhin Wonocolo Surabaya, Skripsi S1, Universitas Islam Negeri Surabaya, diakses $7 \quad$ Agustus 2018, (http://digilib.uinsby.ac.id/19173/1/Abstrak .pdf)

Pemerintah Republik Indonesia, 2003, Undangundang No 20 Tahun 2003 tentang Sistem Pendidikan Nasional, Jakarta, Pemerintah Republik Indonesia.

Sudjana, 2005, Metoda Statistika, Bandung, Tarsito.

Wahyu, Zainul Akhyar, dan Maryana, 2015, Menanamkan Nilai Disiplin Anak pada Lingkungan Keluarga di Desa Sungai Pinang Lama Kecamatan Sungai Tabuk Kabupaten Banjar, Jurnal Pendidikan Kewarganegaraan, vol. 5 no. 10 hh. 853858. 
Wuryandani, W., B. Maftuh, Sapriya, dan D. Budimansyah, 2014, Internalisasi Nilai Karakter Disiplin Melalui Penciptaan Iklim Kelas yang Kondusif di SD Muhammadiyah
Sapen Yogyakarta, Jurna Pendidikan Karakter, vol. 4 no. 2, hh. 175-184. 